\title{
Images in endocrinology: multinodular goitre
}

Imagens em endocrinologia: bócio multinodular

\section{Umberto G. Rossi', Maurizio Cariati'}

A 78-year-old female patient of countryside arrived to general practitioner (GP) for medial cervical mass with reported slow growing (about 50 years) and recent superficial vein dilatation noted by her daughter. On clinical examination the diagnosis of multinodular goitre visible at distance with extrinsically right innominate vein superior vena cava compression and subcutaneous collateral vein formation was done (Figure 1). Patient underwent ultrasound scan that demonstrate increase volume of thyroid gland with partial substernal extension (incomplete intrathoracic goitre), heterogeneous morphology without well-defined nodules, areas of possible hemorrhage and focal calcifications (Figure 2). Patient was selected for thyroid surgery.

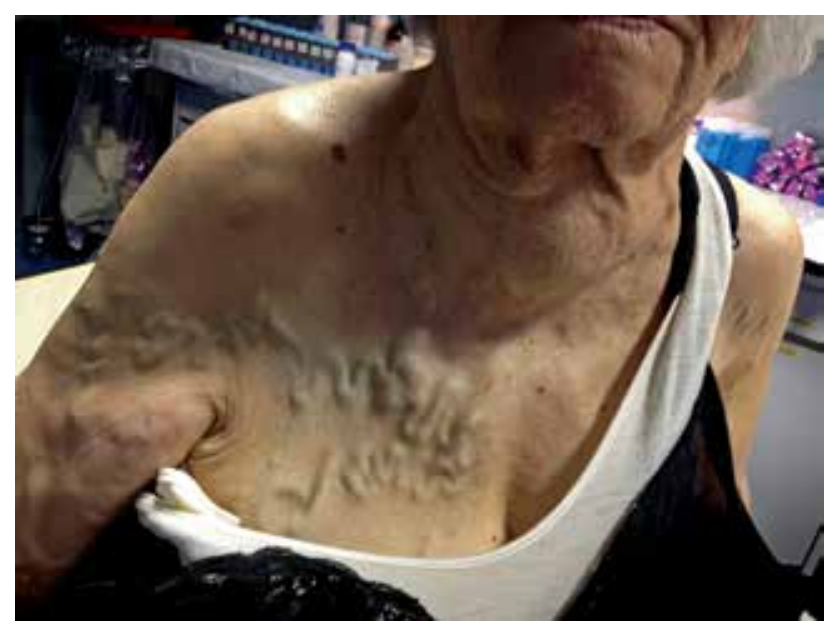

Figure 1. Patient's photo that showing presence of visible multinodular goitre and subcutaneous collateral vein dilatation.

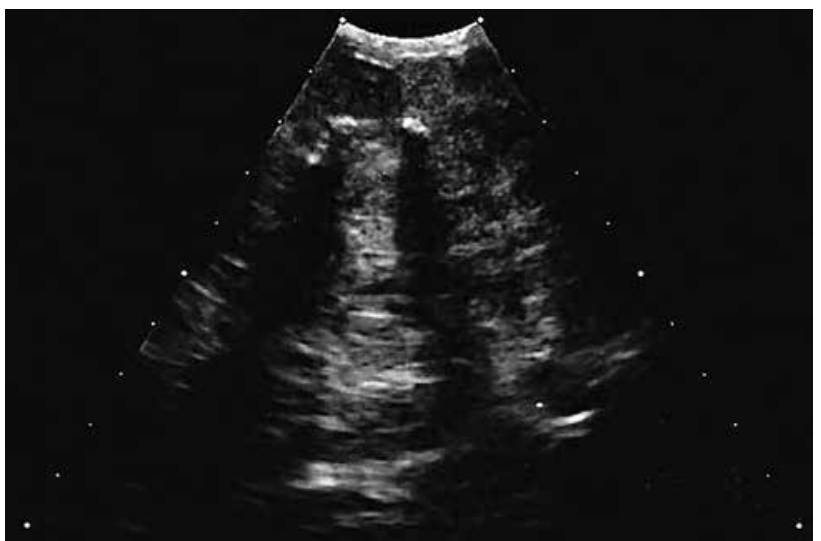

Figure 2. Sagittal ultrasound scan showing increase size of thyroid gland with heterogeneous echogenicity with intraparenchymal calcifications and a maximum thickness of $9.7 \mathrm{~cm}$.
' Department of Diagnostic Sciences, Division of Radiology and Interventional Radiology, San Carlo Borromeo Hospital

Correspondence to:

Umberto G. Rossi

Department of Diagnostic Sciences,

Division of Radiology and

Interventional Radiology

San Carlo Borromeo Hospital

Via Pio 11,3

20153 - Milano, Italy

urossi76@hotmail.com

Received on June/23/2014

Accepted on Aug/10/2014

DOI: 10.1590/0004-2730000003549 
Goitre is defined as any enlarged thyroid that is palpable and/or visible (1), and it can present with either clinical symptoms of excess or under production of the hormone, or with pressure effects on surrounding structures (2). The current definition of intrathoracic goitre is a thyroid gland that is mostly located into the thoracic inlet (3). His definition can be further classified as an "incomplete" or a "complete" intrathoracic goitre. When it is "incomplete" the major portion of the gland is visible on the neck, with its lower pole being substernal, subclavicular or intrathoracic. Consequently, a "complete" intrathoracic goitre is when the gland is completely into the mediastinum (4).

Generally, thyroid disease, as all endocrine diseases, evolves slowly; in particularly multiple adenomatous goitre. So, often it may be missed for years by a person who is seeing the patient regularly, and it will come to physician attention when acute changes happened $(2,4)$. This lowly growing of the goitre, compress in years surrounding tissue as veins, giving time to create superficial venous collaterals (5). The treatment of clinical complicated goitre is surgery, since the complications a relatively rare (6).

Author contributions: Umberto G. Rossi (imaging and writing); Maurizio Cariati (writing).

Disclosure: no potential conflict of interest relevant to this article was reported.

\section{REFERENCES}

1. WHO, UNICEF \& ICCIDD. Indicators for assessing iodine deficiency disorders and their control through salt iodization. $\mathrm{WHO} /$ NUT/94.6. Geneva:WHO, 1994.

2. Jayakumar RV. Clinical approach to thyroid disease. J Assoc Physicians India. 2011;59 Suppl:11-3.

3. deSouza FM, Smith PE. Retrosternal goiter. J Otolaryngol. 1983;12(6):393-6.

4. Pace-Asciak $P$, Higgins $K$. Management of intrathoracic goitre. Can J Surg. 2008;51(5):E111-2.

5. Hans-Joachim A. Compression syndromes caused by substernal goitres. Postgrad Med J. 1998;74:327-9.

6. Netterville JL, Coleman SC, Smith JC, Smith MM, Day TA, Burkey BB. Management of substernal goiter. Laryngoscope. 1998;108:1611-7. 